\title{
Future pesticide risk assessment: narrowing the gap between intention and reality
}

\author{
Ralf B. Schäfer ${ }^{1 *} \mathbb{D}$, Matthias Liess ${ }^{2,3}$, Rolf Altenburger ${ }^{3,4}$, Juliane Filser ${ }^{5}$, Henner Hollert ${ }^{3}$, Martina Roß-Nickoll ${ }^{3}$, \\ Andreas Schäffer ${ }^{3^{*}}$ and Martin Scheringer ${ }^{6,7}$
}

\begin{abstract}
Main text
Agrochemicals, such as pesticides and fertilizers, have facilitated an unprecedented intensification of agriculture $[1,2]$. However, the desired yield gains come at the cost of unwanted side effects on the environment. Pesticides have been demonstrated to contribute to the decline of non-target organisms, such as bees, birds and aquatic biodiversity [3-5], fueling the global biodiversity crisis. This runs contrary to global efforts to protect biodiversity and, in particular, also to the aims of the European Union's (EU) pesticide regulation [6]. Consistent exceedances of regulatory thresholds [7] and revisions of authorizations of pesticides, such as of neonicotinoid insecticides in the EU by the Standing Committee on plants, animals, food and feed (PAFF Committee), also attest to deficiencies in regulatory pesticide risk assessment and management.
\end{abstract}

\section{Authorization along tiers}

To authorize a pesticide, risk assessment in the EU [8], the United States of America (USA) [9] and most other countries, requires that the predicted environmental exposure concentration is below a concentration considered safe for non-target organisms (Fig. 1, for details see [10]). In the EU, in a first step (so-called first tier) of the risk assessment, this safe concentration is established by the European Food Safety Authority (EFSA) in cooperation with national agencies of the EU member states through a combination of:

\footnotetext{
*Correspondence: schaefer-ralf@uni-landau.de;

andreas.schaeffer@bio5.rwth-aachen.de

1 Institute for Environmental Sciences, University of Koblenz-Landau,

Fortstraße 7, 76829 Landau, Germany

${ }^{3}$ Institute for Environmental Research, RWTH Aachen University,

Worringerweg 1, 52074 Aachen, Germany

Full list of author information is available at the end of the article
}

- Standard toxicity tests, i.e., tests performed with single chemicals and single species under laboratory conditions without additional stressors, and,

- Safety factors (also called assessment factors) that account for uncertainties in the extrapolation to real ecosystems.

If the predicted exposure exceeds the safe concentration (as is the case for $2 / 3$ of insecticides [7]), a pesticide can still be authorized if the producer can show through further data that its environmental and human health impacts are acceptable [8]. This is formalized as a tiered framework that extends the standard toxicity tests (first tier) to more complex scenarios (higher tiers) [11]. Higher tiers integrate processes and characteristics occurring in natural ecosystems, such as multi-species semi-field test systems in the EU, as well as reduction of exposure through mitigation measures in risk management [8]. The tiered framework relies on two assumptions: (i) the first tier provides an overly protective measure of potential effects in the field; (ii) the higher tiers provide more ecologically relevant predictions of field effects or of concentrations that do not lead to unacceptable effects. Therefore, despite being rewarded with lower safety factors, they are assumed to still be sufficiently protective (Fig. 1). However, the widespread and well-documented occurrence of adverse effects in the field when authorized pesticides are applied (e.g., [3-5, 12-18]) questions these assumptions.

\section{Lacking drivers of risks for ecosystems}

This failure of the current regulation to protect biodiversity has been attributed to inaccurate predictions of both exposure [19, 20] and effects [5], which derive from generic and, essentially, inaccurate representations of 


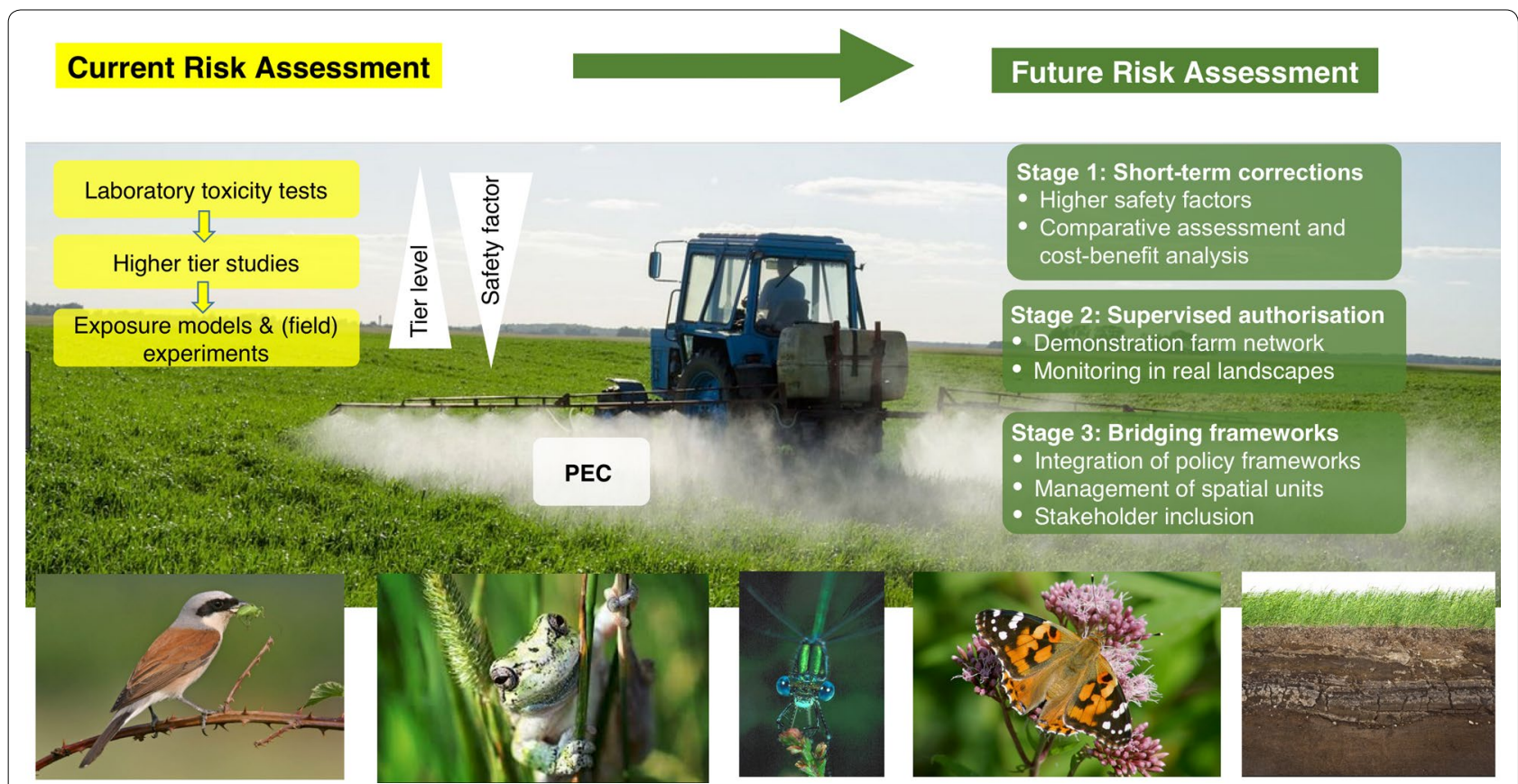

Fig. 1 Simplified scheme of current and suggested future pesticide risk assessment in the EU. Currently, authorization is given as long as the predicted exposure concentration (PEC) does not exceed the predicted no-effect concentration identified by single tiers, multiplied by the respective safety factor. Only substances that fail all tiers are not authorized

ecosystems. Improved predictions for specific, spatially explicit real-world scenarios would require consideration of the following factors in the test systems and models $[21,22]$ :

(i) Ecological context, i.e., the ecological properties such as sensitivity and functions of organisms and the composition of organism communities of the whole ecosystem to be protected.

(ii) Landscape context, i.e., the situation in which the ecosystem is embedded. This comprises general environmental conditions, e.g., habitat type and climate, and site-specific aspects such as the connectivity to other sites and presence of additional stressors.

(iii) Management context, including the farmers' use patterns partly as prescribed by governmental risk managers, e.g., minimum spraying distance to field margin and sequence of pesticide use, that determines the potential occurrence of mixtures of compounds in soils and water bodies, which may exacerbate risks.

Integrating these factors into test systems and models represents a formidable challenge-given that increasing the complexity of test systems comes at the cost of lower reliability and that the models are still in their infancy. As long as a scientifically validated prediction framework has not been established, we suggest procedural and institutional changes for the authorization of pesticides in the EU to narrow the current gap between the intention and reality of protecting biodiversity. The suggested changes are organized in stages (Fig. 1), the implementation of which requires increasing structural adaptation of the current framework and time frames. They are tailored to the EU process but can also inform regulation in other regions.

\section{Stage 1: short-term corrections of the current system}

We suggest an increase in safety factors by a factor of at least 10 for all tiers (cf. [7, 23, 24]) to cover uncertainties arising from the ecological, landscape and management context and to align predicted and observed effects in ecosystems. Moreover, the authorization process should be comparative, i.e., compare the risks of a pesticide product to already authorized products, and include a cost-benefit analysis. The comparative assessment would allow for weighing options, for example, authorizing the product with the lowest environmental side effects [25]. The cost-benefit analysis would compare the costs of potential yield losses to environmental quality benefits. Although quantification may prove elusive for new compounds, minor reductions in yield losses at the cost of further deteriorating the environment would suggest that the product fails the cost-benefit analysis. 
Such developments could be complemented by novel insurance methods that protect farmers from crop failure to reduce the reliance of farmers on pesticides and to avoid that farmers carry the main burden of the suggested changes in risk assessment main burden of the measures [26]. Implementation of these measures would only require relatively minor adaptation of national and European legislation, such as the Commission regulations $1107 / 2009$ and 546/2011, and related guidelines provided by EFSA (e.g., [27]), which should subsequently be adopted quickly by the European Commission (as an example for a slow adoption see [28]), and could be achieved within several months to years. If a pesticide was authorized based on this framework, the rate of exceedance of regulatory thresholds would strongly decrease in most or all landscapes, enhancing environmental safety [7].

\section{Stage 2: supervised provisional authorization as new paradigm}

Implementing stage-1 measures may result in risk assessment that is overprotective in some landscapes. Regulation that more efficiently balances the different ecosystem services (e.g., crop yield, pure drinking water, biodiversity) can be achieved by substituting higher tiers with a provisional authorization. This acknowledges the limitations in predicting (ecological) real-world effects and is guided by the principle of pharmaceutical regulation stipulating that a general-use authorization is only granted after passing trials under real-world conditions. Calls for post-registration monitoring [25, 29, 30] and pesticide vigilance [31] point in a similar direction, but need to be tied to the concept of reserving landscapes and catchments for the purpose of pesticide risk assessment. In these test landscapes and catchments, which should be selected to represent a range of typical land uses, information that is typically non-disclosed such as the farmers' use patterns in terms of dates and doses should be available for the risk assessment. The provisional authorization would require monitoring the fate and effects of pesticide products in these landscapes and catchments, and the final authorization decision would be made in light of the monitoring. Implementation would come at comparatively minor costs as the monitoring could be expanded from the environmental monitoring that is already mandatory in all European member states, and is also conducted in other regions, such as the Japan, Switzerland and USA. In addition, the applicant for an authorization could bear a major part of the costs for the expanded monitoring (but the economic implications particularly for small and medium enterprises should be borne in mind). In Germany, a network of demonstration farms for integrated pest management has been established that provides a starting point for farmscale real-world monitoring of the fate and effects of new pesticides, as well as of the consequences of risk management measures such as field margins. This would need to be expanded to catchments and consequently consider ecological, landscape, and management contexts. The results would make it possible to validate chemical fate and ecological effect models for prospective risk assessment. Once validated, the risk assessment would be based on these models, replacing the supervised provisional authorization. Implementation of this authorization procedure would require far-reaching adaptation of regulations and subsequently the development of EFSA guidelines with fast adoption by the European Commission, as well as the establishment of a European demonstration farm network covering different climatic and land use scenarios, ideally under the auspice of EFSA (see previous section for examples of regulations and guidelines and see the draft guideline for veterinary pharmaceuticals as an example for the integration of monitoring [32]). EFSA's recent considerations on an improved environmental risk assessment of pesticides, e.g., including the landscape and management context (see above), support our demand for a revision of guidelines [22]. Nevertheless, such adaptations may take years to a decade.

\section{Stage 3: bridging legal frameworks, stakeholders, and institutions}

Risk management decisions under the current framework are made with a narrow focus on poorly defined protection goals [25, 33]. In addition, an integration of different policy frameworks, such as those related to nature conservation, water protection, climate protection and agricultural production, is missing [34]. We suggest that a future pesticide regulation framework be integrated into an overall environmental policy framework. Such a framework can build on the cross-compliance principle, which provides direct payments for farmers who maintain their land in good agricultural and environmental condition. A unified guidance and an authorization process by governmental risk managers that consider the requirements of different regulations for biodiversity and populations of species are urgently needed. Irrespective of how the acceptable levels are set, enforcement of these levels would require management of regional domains, which might entail elements of conservation management, such as land sparing, and stakeholder input [35]. For example, highly pesticide-intensive agriculture could be compensated for by setting aside land to buffer the overall toxic exposure in the domain. This means that some side effects would be accepted locally, while the biodiversity targets for the entire domain (landscape types including catchments) are still met. Managing the 
side effects in these spatial domains could be organized analogously to successful other mitigation measures, such as cap and trade schemes, e.g., for sulphur dioxide in the USA and for carbon dioxide in California [36]. Farmers could trade the pesticide emissions, where total emissions of toxicity equivalents would be defined for the spatial domain in addition to maximum residue levels for the crop, ensuring that the ecological and human health targets are met. This requires the adoption of a novel framework and related institutional changes that may take at least a decade, where the implementation may be guided by agro-environmental indicator schemes (e.g., [37]).

\section{Towards stakeholder-driven cooperative land management}

Adopting the suggested changes to current risk assessment not only offers the option to substantially improve our understanding and mitigation of pesticide risks, but also would provide opportunities to combine different measures of land management, including crop rotation and field sizing. If agro-environmental indicators of risk for biodiversity and ecosystem services were defined clearly, stakeholders including industry, political authorities, farmers, and conservationists, would be empowered to improve their local environment by means most suitable for them [38]. This could entail structural improvements for ecosystem connectivity, reduced pesticide use, creation of refuges, and other measures [26, 39]. Eventually, a more realistic risk assessment process should include all stakeholders' interests through cooperation to meet their common needs and values. No economic profit can be more valuable than sharing the responsibility for sustaining society's indispensable life support system while providing sufficient food, clean air, and drinking water. Key to this is healthy ecosystems-and the services provided by a diverse community of plants, animals and microorganisms.

\author{
Abbreviations \\ EFSA: European Food Safety Authority; EU: European Union; PEC: Predicted \\ Exposure Concentration; USA: United States of America.
}

\section{Authors' contributions}

Conceptualization: AS, MRN; investigation: RBS, ML, RA, JF, MRN, AS, MS; visualization: $\mathrm{HH}, \mathrm{RBS}, \mathrm{MRN}, \mathrm{AS}$, JF; writing —original draft preparation: RBS, ML, AS; writing — review \& editing: all. All authors read and approved the final manuscript.

\section{Author details}

1 Institute for Environmental Sciences, University of Koblenz-Landau, Fortstraße 7, 76829 Landau, Germany. ${ }^{2}$ Department System-Ecotoxicology, UFZ, Helmholtz Centre for Environmental Research, Permoserstraße15, 04318 Leipzig, Germany. ${ }^{3}$ Institute for Environmental Research, RWTH Aachen University, Worringerweg 1, 52074 Aachen, Germany. ${ }^{4}$ Department Bioanalytical
Ecotoxicology, UFZ, Helmholtz Centre for Environmental Research, Permoserstraße15, 04318 Leipzig, Germany. ${ }^{5}$ University of Bremen, UFT, General and Theoretical Ecology, Leobener Str., 28359 Bremen, Germany. ${ }^{6}$ Institute of Biogeochemistry and Pollutant Dynamics, ETH Zürich, 8092 Zurich, Switzerland. ${ }^{7}$ Masaryk University, RECETOX, 62500 Brno, Czech Republic.

\section{Acknowledgements}

The authors acknowledge comments on the manuscript by two anonymous reviewers as well as Jason Rohr, Juliane Hollender, Ralf Schulz, Paul van den Brink, Inge Werner, Jörg Römbke, Francisco Sanchez-Bayo and Ben Kefford who helped to improve the manuscript. Moreover, the authors acknowledge the Leopoldina workshop participants contributing to the discussion: Christian Anton, Detlev Drenckhahn, Tobias Frische, Mark Gessner, Detlev Drenckhahn, Maximilian Hempel, Janet Hering, Wolfgang Köck, Werner Kratz, Ernst-August Nuppenau, Bernd Stein, Henning Steinicke.

\section{Competing interests}

$\mathrm{HH}$ is the Editor-in-Chief of the journal Environmental Sciences Europe in which this article is published. The authors declare that they have no competing interests.

\section{Availability of data and materials \\ Not applicable.}

\section{Consent for publication}

Not applicable.

\section{Ethics approval and consent to participate}

Not applicable.

\section{Funding}

The paper evolved from a workshop funded by the German National Academy of Sciences Leopoldina.

\section{Publisher's Note}

Springer Nature remains neutral with regard to jurisdictional claims in published maps and institutional affiliations.

Received: 23 January 2019 Accepted: 8 March 2019

Published online: 03 April 2019

\section{References}

1. Stanton RL, Morrissey CA, Clark RG (2018) Analysis of trends and agricultural drivers of farmland bird declines in North America: a review. Agric Ecosyst Environ 254:244-254. https://doi.org/10.1016/j.agee.2017.11.028

2. Tilman D, Balzer C, Hill J, Befort BL (2011) Global food demand and the sustainable intensification of agriculture. Proc Natl Acad Sci U S A 108:20260-20264. https://doi.org/10.1073/pnas.1116437108

3. Beketov MA, Kefford BJ, Schäfer RB, Liess M (2013) Pesticides reduce regional biodiversity of stream invertebrates. Proc Natl Acad Sci U S A 110:11039-11043. https://doi.org/10.1073/pnas.1305618110

4. Rundlöf M, Andersson GKS, Bommarco R et al (2015) Seed coating with a neonicotinoid insecticide negatively affects wild bees. Nature 521:77-80. https://doi.org/10.1038/nature14420

5. Hallmann CA, Foppen RPB, van Turnhout CAM et al (2014) Declines in insectivorous birds are associated with high neonicotinoid concentrations. Nature 511:341-343. https://doi.org/10.1038/nature13531

6. EEC (2009) Directive 2009/128/EC of the European Parliament and of the Council of 21 October 2009 establishing a framework for Community action to achieve the sustainable use of pesticides

7. Stehle S, Schulz R (2015) Pesticide authorization in the EU-environment unprotected? Environ Sci Pollut Res. https://doi.org/10.1007/s1135 6-015-5148-5

8. EU (2011) Commission Regulation (EU) No 546/2011 of 10 June 2011 implementing Regulation (EC) No 1107/2009 of the European Parliament and of the Council as regards uniform principles for evaluation and authorisation of plant protection products. Official Journal of the European Union, Brussel 
9. United States Congress (1910) An Act for preventing the manufacture sale, or transportation of adulterated or misbranded Paris greens, lead arsenates, and other insecticides, and also fungicides, and for regulating traffic therein and for other purposes

10. Boivin A, Poulsen V (2017) Environmental risk assessment of pesticides: state of the art and prospective improvement from science. Environ Sci Pollut Res 24:6889-6894. https://doi.org/10.1007/s11356-016-8289-2

11. Rohr JR, Salice CJ, Nisbet RM (2016) The pros and cons of ecological risk assessment based on data from different levels of biological organization. Crit Rev Toxicol 46:756-784. https://doi.org/10.1080/10408 444.2016.1190685

12. Sánchez-Bayo F, Wyckhuys KAG (2019) Worldwide decline of the entomofauna: a review of its drivers. Biol Conserv 232:8-27. https://doi. org/10.1016/j.biocon.2019.01.020

13. Mingo V, Lötters S, Wagner N (2017) The impact of land use intensity and associated pesticide applications on fitness and enzymatic activity in reptiles-a field study. Sci Total Environ 590-591:114-124. https://doi. org/10.1016/j.scitotenv.2017.02.178

14. Wood TJ, Goulson D (2017) The environmental risks of neonicotinoid pesticides: a review of the evidence post 2013. Environ Sci Pollut Res 24:17285-17325. https://doi.org/10.1007/s11356-017-9240-x

15. Frische T, Egerer S, Matezki S et al (2018) 5-Point programme for sustainable plant protection. Environ Sci Eur 30:8. https://doi.org/10.1186/s1230 2-018-0136-2

16. Graf N, Battes KP, Cimpean M et al (2019) Do agricultural pesticides in streams influence riparian spiders? Sci Total Environ 660:126-135. https:// doi.org/10.1016/j.scitotenv.2018.12.370

17. Knillmann S, Orlinskiy P, Kaske $O$ et al (2018) Indication of pesticide effects and recolonization in streams. Sci Total Environ 630:1619-1627. https:// doi.org/10.1016/j.scitotenv.2018.02.056

18. Zubrod JP, Bundschuh M, Arts G et al (2019) Fungicides_-an overlooked pesticide class?. In press, Enviromental Sci Technol

19. Knäbel A, Stehle S, Schäfer RB, Schulz R (2012) Regulatory FOCUS surface water models fail to predict insecticide concentrations in the field. Environ Sci Technol 46:8397-8404

20. Knäbel A, Meyer K, Rapp J, Schulz R (2014) Fungicide field concentrations exceed FOCUS surface water predictions: urgent need of model improvement. Environ Sci Technol 48:455-463. https://doi.org/10.1021/es404 8329

21. Schäffer A, Filser J, Frische T, et al (2018) The silent spring-on the need for sustainable plant protection. German National Academy of Sciences Leopoldina, Halle. https://www.leopoldina.org/uploads/tx_leopublica tion/2018_Diskussionspapier_Pflanzenschutzmittel_EN_02.pdf. Accessed Mar 2019

22. Streissl F, Egsmose M, Tarazona JV (2018) Linking pesticide marketing authorisations with environmental impact assessments through realistic landscape risk assessment paradigms. Ecotoxicology 27:980-991. https:// doi.org/10.1007/s10646-018-1962-0

23. Schäfer RB, von der Ohe P, Rasmussen J et al (2012) Thresholds for the effects of pesticides on invertebrate communities and leaf breakdown in stream ecosystems. Environ Sci Technol 46:5134-5142. https://doi. org/10.1021/es2039882

24. Liess M, Beketov M (2011) Traits and stress: keys to identify community effects of low levels of toxicants in test systems. Ecotoxicology 20:1328-1340. https://doi.org/10.1007/s10646-011-0689-y
25. European Commission, Directorate-General for Research and Innovation (2018) EU authorisation processes of plant protection products from a scientific point of view, Group of Chief Scientific Advisors. Publications Office of the European Union, Luxembourg

26. Furlan L, Pozzebon A, Duso C et al (2018) An update of the Worldwide Integrated Assessment (WIA) on systemic insecticides. Part 3: alternatives to systemic insecticides. Environ Sci Pollut Res 1:1. https://doi. org/10.1007/s11356-017-1052-5

27. EFSA (2013) Guidance on tiered risk assessment for plant protection products for aquatic organisms in edge-of-field surface waters. EFSA J 11:3290. https://doi.org/10.2903/j.efsa.2013.3290

28. EC (2002) Guidance Document on Aquatic Ecotoxicology in the context of the Directive 91/414/EEC. Directorate E-Food Safety: plant health, animal health and welfare, international questions, Brussels, Belgium

29. Vijver MG, Hunting ER, Nederstigt TAP et al (2017) Postregistration monitoring of pesticides is urgently required to protect ecosystems. Environ Toxicol Chem 36:860-865. https://doi.org/10.1002/etc.3721

30. Römbke J, Duis K (2018) Proposal for a monitoring concept for veterinary medicinal products with PBT properties, using parasiticides as a case study. Toxics 6:14. https://doi.org/10.3390/toxics6010014

31. Milner AM, Boyd IL (2017) Toward pesticidovigilance. Science 357:12321234. https://doi.org/10.1126/science.aan2683

32. CMVP (2016) Draft guideline on the higher tier testing of veterinary medicinal products to dung fauna. https://www.ema.europa.eu/en/ documents/scientific-guideline/draft-guideline-higher-tier-testing-veter inary-medicinal-products-dung-fauna_en.pdf. Accessed Mar 2019

33. Brown AR, Whale $G$, Jackson $M$ et al (2017) Toward the definition of specific protection goals for the environmental risk assessment of chemicals: a perspective on environmental regulation in Europe: defining Environmental protection goals for chemicals. Integr Environ Assess Manag 13:17-37. https://doi.org/10.1002/ieam.1797

34. Brack W, Dulio V, Ågerstrand M et al (2017) Towards the review of the European Union water framework management of chemical contamination in European surface water resources. Sci Total Environ 576:720-737. https://doi.org/10.1016/j.scitotenv.2016.10.104

35. Phalan B, Onial M, Balmford A, Green RE (2011) Reconciling food production and biodiversity conservation: land sharing and land sparing compared. Science 333:1289-1291. https://doi.org/10.1126/Science.1208742

36. Bang G, Victor DG, Andresen S (2017) California's cap-and-trade system: diffusion and lessons. Glob Environ Polit 17:12-30. https://doi. org/10.1162/GLEP_a_00413

37. European Environment Agency (2006) Integration of environment into EU agriculture policy - the IRENA indicator-based assessment report. Office for Official Publications of the European Communities, Luxembourg

38. Maltby L, van den Brink PJ, Faber JH, Marshall S (2018) Advantages and challenges associated with implementing an ecosystem services approach to ecological risk assessment for chemicals. Sci Total Environ 621:1342-1351. https://doi.org/10.1016/j.scitotenv.2017.10.094

39. Lechenet M, Dessaint F, Py G et al (2017) Reducing pesticide use while preserving crop productivity and profitability on arable farms. Nat Plants 3:17008 